\title{
Low carbohydrate diet in type 1 diabetes, long-term improvement and adherence: A clinical audit
}

\author{
Jørgen Vesti Nielsen ${ }^{1 *}$, Caroline Gando², Eva Joensson ${ }^{2}$ and Carina Paulsson ${ }^{2}$
}

\begin{abstract}
Background: Reduction of dietary carbohydrates and corresponding insulin doses stabilizes and lowers mean blood glucose in individuals with type 1 diabetes within days. The long-term adherence for persons who have learned this technique is unknown. To assess adherence over 4 years in such a group the present audit was done retrospectively by record analysis for individuals who have attended an educational course. Adherence was assessed from HbA1c changes and individuals' own reports.

Findings: Altogether 48 persons with diabetes duration of $24 \pm 12$ years and $\mathrm{HbA} 1 \mathrm{c}>=6.1 \%$ (Mono-S; $\mathrm{DCCT}=7.1 \%)$ attended the course. Mean HbA1c for all attendees was at start, at 3 months and 4 years $7.6 \% \pm 1.0 \%$, $6.3 \pm 0.7 \%, 6.9 \pm 1.0 \%$ respectively. The number of non-adherent persons was $25(52 \%)$. HbA1c in this group was at start, at 3 months and 4 years: $7.5 \pm 1.1 \%, 6.5 \pm 0.8 \%, 7.4 \pm 0.9 \%$. In the group of 23 (48\%) adherent persons mean $\mathrm{HbA1C}$ was at start, at 3 months and 4 years $7.7 \pm 1.0 \%, 6.4 \pm 0.9 \%, 6.4 \pm 0.8 \%$.

Conclusion: Attending an educational course on dietary carbohydrate reduction and corresponding insulin reduction in type 1 diabetes gave lasting improvement. About half of the individuals adhered to the program after 4 years. The method may be useful in informed and motivated persons with type 1 diabetes. The number needed to treat to have lasting effect in 1 was 2.
\end{abstract}

Keywords: Low-carbohydrate, Diet, Type 1 diabetes, Adherence, HbA1c, IFCC

\section{Background}

Considering the detrimental effect of hyperglycemia upon all organ systems the achieving of euglycemia or near-euglycemia is essential in the care of type 1 diabetes $[1,2]$. However, lowering of the mean HbA1c in DCCT (Diabetes and Control Trial) increased the rate of severe hypoglycemia threefold [1]. Despite technological progress such as self monitoring, use of insulin delivery devices (pens, pumps) the average glycemic control in type 1 diabetes is poor. In Sweden mean HbA1c in adults is about 7\% (Mono-S method, corresponding to about $8 \%$ DCCT and $63 \mathrm{mmol} / \mathrm{mmol}$, IFCC).

The blood glucose excursions in type 1 diabetes are a function of the input of glucose from food, mainly carbohydrates in the form of easily dissolved starch and sugars,

\footnotetext{
* Correspondence: jvesti_nielsen@hotmail.com

'Formerly Department of Medicine, Blekingesjukhuset, Karlshamn, 37480 Karlshamn, Sweden

Full list of author information is available at the end of the article
}

and insulin from subcutaneous insulin stores. The estimation of the amount of carbohydrates in a meal has an error rate of $50 \%$ [3]. The insulin absorption may vary by up to $30 \%$ [4]. It is therefore virtually impossible to match carbohydrates and insulin which leads to unpredictable blood glucose levels after meals. By reducing the carbohydrates and insulin doses the size of the blood glucose fluctuations can be minimized. The risk of hypoglycemia is therefore minimized as well $[5,6]$. Around-the-clock euglycemia was seen with $40 \mathrm{~g}$ carbohydrates in a group of people with type 1 diabetes [7].

The immediate resulting stable, near-normal blood glucose levels allow individuals to predict after-meal glucose levels with great accuracy (see Figure 1). This regimen is little used, but can be an added important approach for some patients. Also in type 2 diabetes is reduction of dietary carbohydrates a useful regimen with lasting effect on all aspect of the metabolic syndrome [8].

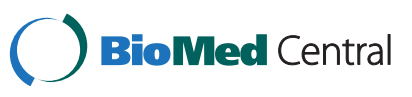

(c) 2012 Nielsen et al.; licensee BioMed Central Ltd. This is an Open Access article distributed under the terms of the Creative Commons Attribution License (http://creativecommons.org/licenses/by/2.0), which permits unrestricted use, distribution, and reproduction in any medium, provided the original work is properly cited. 


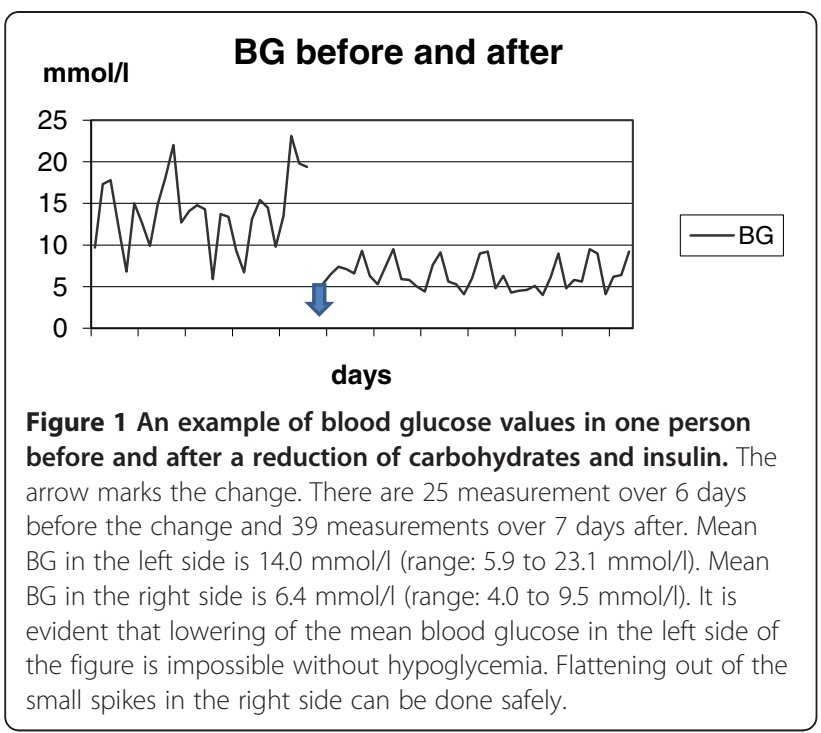

For individuals with type 1 diabetes one year audit/ evaluation of group education in this regimen has shown that the short-time lowering of mean $\mathrm{HbA} 1 \mathrm{c}$ by 1 percentage unit and the reduction in mean rate of symptomatic hypoglycemia by $82 \%$ was maintained [9].

All individuals attending the educational course here have sought it themselves after having had written information of the regimen. It is practical guidance based on the central medicine sciences of physiology, biochemistry and pharmacology. It is aimed at normalizing the blood glucose $[5,6]$. This approach in almost all individuals gives the sought effect immediately. But since participants in diet studies generally show very poor adherence to whatever diet they are put on, we have again done an audit. The purpose is to map adherence among the individuals with type 1 diabetes, who attended the educational course at least 4 years earlier.

\section{Methods}

\section{Attendees}

The attendees were all outpatients. All individuals with HbA1c $>=6.1 \%$ (DDCT: $7.1 \%$ ) attending the educational course from the start of 2004 to 2006 and adhering to it for at least the first 4 weeks are reported here. All patients, dissatisfied with their own glucose control and looking for ways to improve it, have received complete information about carbohydrates' effect on their blood glucose and the effect of a reduction. It was then up to themselves to decide whether they wished to make any changes.

Individuals attended the course in groups of 5-7 people. The course consisted of one whole day followed by 4 sessions lasting 2-3 hours once a week over 4 weeks. The regimen is a carbohydrate restricted diet (carbohydrates $75 \mathrm{~g} /$ day or less) in combination with correspondingly adapted insulin doses. The method is described elsewhere [9]. An additional file shows the methods in more detail [see additional file 1].

\section{Adherence}

Adherence was estimated from both HbA1c changes and an individual's self reported adherence. The blood glucose changes the first days show the effect of the regimen; HbA1c after 3 months shows the effect of short-time adherence. From then on we have assessed adherence by comparing individual $\mathrm{HbA} 1 \mathrm{c}$ values with the start and 3-months values. HbA1c continuously at 3 months level or lower suggests good adherence, and vice versa. Information about adherence to the diet was obtained from each individual's own report in the clinical chart.

\section{$\mathrm{HbA1c}$}

Some people have a seasonal variation of HbA1c. The difference in $\mathrm{HbA1c}$ over a year appears to be related to the difference in temperature [10]. For each person we have therefore primarily used HbA1c taken the same months each year. If a value was missing the mean of the two adjacent $\mathrm{HbA1cs}$ are used.

HbA1c measurements were done in the same laboratory using the Mono-S method used in Sweden. This method gives values approximately 1 percentage unit lower than DCCT units. HbA1c (Mono-S) of $6.0 \%$ and $8.0 \%$ corresponds to HbA1c (DCCT) of approximately $7.0 \%$ and $9.0 \%$ respectively. This corresponds to $52 \mathrm{mmol} / \mathrm{mol}$ and $84 \mathrm{mmol} / \mathrm{mol}$ in IFCC units which is used in some places of Europe (IFCC = International Federation of Clinical Chemistry and Laboratory Medicine). Normal values for people below 50 years are: $($ Mono-S) $<5.5 \%$, (DCCT) $<6.5 \%$ and (IFCC) $<46 \mathrm{mmol} / \mathrm{mol}$.

Normal/near normal $(<6 \%)$ HbA1c values cannot be expected to change much and are therefore not suitable to evaluate adherence in this report. Mono-S (\%) to IFCC $(\mathrm{mmol} / \mathrm{mol})=10.45^{*}[\mathrm{HbA} 1 \mathrm{c}]-10.67$.

\section{Statistics}

Means are given with standard deviation. Two-tailed $t$-test for dependent samples is used.

\section{Results}

Altogether 48 persons with HbA1c $>6.1 \%$ (DCCT: 7.1\%) had attended the course, 31 women and 17 men. This is $16 \%$ of all the patients connected to the present diabetes unit. Three persons came the first day but cancelled the next visit. All the individuals were known to us. Most had attended diabetes education before in the form of diabetes schools, diabetes camps etc. Fourteen used insulin pumps. There was no relation between the use of 
the pumps and HbA1c. Mean age and diabetes duration was $52 \pm 11.5$ years and $24.0 \pm 12$ years respectively. Seven individuals with gatro-paresis used domperidone (motilium) in order to improve gastric motility.

\section{Weight, lipids and insulin}

Table 1 shows mean weight and Body Mass Index $\left(\mathrm{kg} / \mathrm{m}^{2}\right)(\mathrm{BMI})$ and lipids. In the group of adherent people following changes were seen after 4 years: Mean Tot-Chol. from $5.3 \pm 0.9$ to $5.6 \pm 0.8 \mathrm{mmol} / \mathrm{l}(\mathrm{p}=0.04)$. The increase was caused by an HDL increase from $1.5 \pm 0.5$ to $1.8 \pm 0.4 \mathrm{mmol} / \mathrm{l}(\mathrm{p}=0.04)$. TAG was almost unchanged. Ratio Chol/HDL was 3.6 and $3.2(\mathrm{p}=0.035)$; ratio TAG/HDL was 0.5 and $0.4(\mathrm{P}=0.04)$ at start and after 4 years respectively.

Meal insulin was reported for 36 patients. Mean daily dosage changed as follows: at start $23 \pm 9$ IU; 1 year $13 \pm 6$ IU. After 4 years the doses were only sporadically reported. We have therefore not reported a mean. Mean long-acting insulin: there was a modest change from $19.6 \pm 5$ IU to $18.6 \pm 6$ IU the first year.

\section{$\mathrm{HbA1c}$}

Forty eight persons with a HbA1c >6.1 attended the course and could, based on HbAlc response and their own information in the chart be divided in non-adherent and adherent individuals. All achieved the expected mean HbA1c reduction after 3 months. After 2 years and onwards however, 25 persons (52\%) had reverted with respect to both mean $\mathrm{HbA} 1 \mathrm{c}$ and diet. There are 4 designations in table and figure. Their meanings are: $\mathrm{A}=$ all patients; $\mathrm{B}=$ non-adherent; $\mathrm{C}=$ partly adherent with intra-person variations over time; $\mathrm{D}=$ adherent.

Table 1 Mean weight and lipids in $\mathbf{4 8}$ patients with type 1 diabetes before and after 4 years of carbohydrate reduction

\begin{tabular}{llllll}
\hline & Start & $\mathbf{3}$ months & $\mathbf{P ( 1 )}$ & $\mathbf{4}$ years & $\mathbf{P ( 2 )}$ \\
\hline Weight(kg) & $\mathbf{7 7 . 6} \pm 15$ & $\mathbf{7 4 . 9} \pm 13.9$ & $<0.001$ & $\mathbf{7 6 . 7} \pm 14.6$ & 0.18 \\
BMl $\left(\mathrm{Kg} / \mathrm{m}^{2}\right)$ & $\mathbf{2 5 . 9} \pm 3.5$ & $\mathbf{2 5 . 0} \pm 3.4$ & $<0.001$ & $\mathbf{2 5 . 7} \pm 3.8$ & 0.22 \\
$\begin{array}{l}\text { Tot-cholesterol } \\
\text { (mmol/l) }\end{array}$ & $\mathbf{5 . 4} \pm 1$ & $\mathbf{5 . 6} \pm 1.0$ & 0.2 & $\mathbf{5 . 6} \pm 0.9$ & 0.44 \\
$\begin{array}{l}\text { HDL-cholesterol } \\
\text { (mmol/l) }\end{array}$ & $\mathbf{1 . 5} \pm 0.4$ & $\mathbf{1 . 6} \pm 0.5$ & 0.03 & $\mathbf{1 . 7} \pm 0.4$ & $<0.001$ \\
$\begin{array}{l}\text { Triacylglycerol(TAG) } \\
\text { (mmol/l) }\end{array}$ & $\mathbf{0 . 9} \pm 0.8$ & $\mathbf{0 . 8} \pm 0.5$ & 0.04 & $\mathbf{0 . 9} \pm 0.4$ & 0.73 \\
Ratio Chol/HDL & $\mathbf{3 . 9} \pm 1.2$ & $\mathbf{3 . 5} \pm 1.4$ & 0.11 & $\mathbf{3 . 5} \pm 1.0$ & $<0.001$ \\
Ratio TAG/HDL & $\mathbf{0 . 8} \pm 1.2$ & $\mathbf{0 . 6} \pm 0.9$ & $<0.001$ & $\mathbf{0 . 6} \pm 0.5$ & 0.08
\end{tabular}

$\mathrm{P}(1)$ the $\mathrm{p}$-value is for the difference between start and 3 months. $\mathrm{P} 2$ ) the $p$ value is for the difference between start and 4 years. TAG: triacylglycerols; HDL: HDL-cholesterol; Chol: cholesterol.

The carbohydrates amount was reduced to $75 \mathrm{~g} /$ day or lower according to the patient's own preferences. The insulin doses reduced according to the quantity of carbohydrates.
The HbA1c changes in the groups are seen in Table 2 and Figure 2.

\section{Cardiovascular disease}

One person underwent percutanous coronary intervention in the 4 years.

\section{Discussion}

After 2 years about half of the individuals had ceased adhering. The other half (group $\mathrm{C}+\mathrm{D}$ ) achieved a stable lowering of HbA1c. This is clinically significant. The tissue destructions from hyperglycemia accumulate steeply in the type 1 diabetes population [1]. The HbAc1 reduction therefore, even in this little group, already after a few years corresponds to a number of people avoiding complications [1].

The calculated number of persons who have avoided complications over 4 years among the 23 persons are: Retinopathy progression $2-3$ persons $(8-11 \%)$; laser treatment 1 person (4\%); neuropathy $5-6$ persons $(22-26 \%)$; severe retinopathy 1 (4\%). About 1 person (4\%) per 5 years can be expected to avoid macular edema, and 1 person to avoid a cardiovascular event $[1,2]$.

The ratio Chol/HDL is a marker of a specific risk for myocardial infarction [11]. The changes here correspond to a $20 \%$ reduction in this risk. The difference in HbA1c reduces the risk of cardiovascular disease by about $40 \%$ $[1,2]$. Substitution of fat for carbohydrates is generally more beneficial for risk of cardiovascular disease in both normal- and overweight persons than the widely recommended low-fat diet [12].

There is no reason to assume that the patients here are different from the rest of Sweden. The number of adults with type 1 diabetes in Sweden is about 40,000 and the number cared for by the present diabetes unit is about 300 .

The 23 persons in group $\mathrm{C}+\mathrm{D}$ constitute about $7.6 \%$ of all persons with type 1 diabetes cared for by the

\begin{tabular}{|c|c|c|c|c|c|c|c|c|}
\hline §Group & $n$ & $\%$ & start & $3 \mathrm{mo}$. & 4 years & *Change & $\%$ & $! p$ \\
\hline$\overline{\text { All }}$ & 48 & 100 & $7.6 \pm 1.0$ & $\mathbf{6 . 3} \pm 0.7$ & $6.9 \pm 1.0$ & $-0.7 \pm 1.1$ & $-8.4 \pm 13$ & $<0.001$ \\
\hline B & 25 & 52 & $\mathbf{7 . 5} \pm 1.1$ & $\mathbf{6 . 5} \pm 0.8$ & $\mathbf{7 . 4} \pm 0.9$ & $-0.1 \pm 0.3$ & $-0.7 \pm 11$ & 0.7 \\
\hline$C+D$ & 23 & 48 & $\mathbf{7 . 7} \pm 1.0$ & $\mathbf{6 . 4} \pm 0.9$ & $\mathbf{6 . 4} \pm 0.8$ & $-1.3 \pm 0.9$ & $-16 \pm 10$ & $<0.001$ \\
\hline C & 10 & 21 & $\mathbf{7 . 6} \pm 1.0$ & $\mathbf{6 . 3} \pm 0.8$ & $\mathbf{6 . 9} \pm 0.8$ & $-0.7 \pm 0.4$ & $-8.8 \pm 4$ & $<0.001$ \\
\hline D & 13 & 27 & $\mathbf{7 . 8} \pm 1.0$ & $\mathbf{6 . 5} \pm 0.8$ & $\mathbf{6 . 0} \pm 0.6$ & $-1.8 \pm 0.9$ & $-22.4 \pm 8$ & $<0.001$ \\
\hline
\end{tabular}

$\S$ A: all patients. B: non-adherent patients. C: partly adherent with intra-person variations over time. D: with initial high $\mathrm{HbA1c}$ and excellent adherence. ${ }^{*}$ The $\mathrm{HbA1C}$ change between start and 4 years in HbA1c units. ! P-values are for differences between start and 4 years.

Carbohydrates (mostly starch) were reduced to $75 \mathrm{~g} /$ day or lower. Insulin doses adapted to the quantity of carbohydrates. 

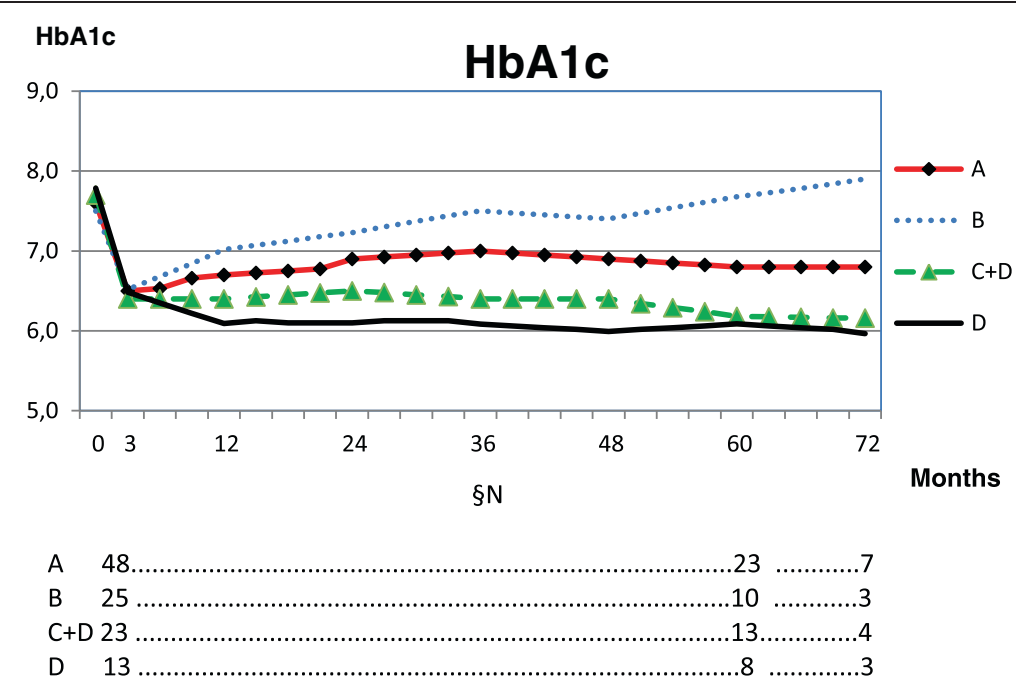

Figure 2 Mean HbA1c over 4 years after reduction of carbohydrates in all and in subgroups with different degrees of adherence. The amount of carbohydrates was $75 \mathrm{~g} /$ day or less according to the person's own preferences. Mainly, starchy food was reduced. The insulin doses were adapted accordingly. $\S \mathrm{N}$ number of patients in groups. $\mathrm{A}=$ all patients (100\%). B = non adherent (52\%). C = partly adherent with intra-person variations over time. $\mathrm{D}=$ excellent adherence (27\%). C +D (47\%).

present unit. The figures in group $\mathrm{C}+\mathrm{D}$ correspond to about 3,100 adults with type 1 diabetes in Sweden who might be expected to adapt to the present approach and avoid a substantial number of complications.

A small group D, $27 \%$ of the subjects, without exception adapted excellently and achieved a constant mean HbA1c lowering by 1.8 percentage point. This group constitutes about $4.3 \%$ of all individuals with type 1 diabetes connected to the present unit, and corresponds to about 1,700 of all adults with type 1 diabetes in Sweden.

Only a limited number of patients, about $16-18 \%$, in contact with the present unit have been interested in such a change of diet as described.

There is no evidence for the use of the widely recommended high-carbohydrate, low-fat diet in type 1 diabetes.

There is no evidence that animal fat in the food should cause cardiovascular disease [13-15]. There is no evidence that protein should cause kidney disease [16]; on the contrary, hyperglycemia gave a 3.5 times higher incidence of albuminuria in DCCT, not protein [1]. There is, however, strong evidence for the aggressive development of damages in all organs in poorly regulated type 1 diabetes [1].

The physician and the individual must therefore together explore the tools and methods that give best result, for instance type of insulin, insulin pens, insulin pump etc. and diet. The restricted carbohydrate dietary approach is directly aimed at lowering of HbA1c, not at avoiding fat and protein. The model described here may be an option for $10-20 \%$ of the patients with type 1 diabetes.

\section{Conclusion}

An educational program involving a low-carbohydrate diet and correspondingly reduced insulin doses for informed individuals with type 1 diabetes gives acceptable adherence after 4 years. One in two people attending the education achieves a long-term significant HbA1c reduction.

\section{Additional file}

Additional file 1: Method details.

\section{Competing interests}

The authors declare that they have no competing interests.

\section{Authors' contribution}

JVN wrote the manuscript and analysed the data. All authors collected data and gave final approval to the manuscript.

\section{Author details}

${ }^{1}$ Formerly Department of Medicine, Blekingesjukhuset, Karlshamn, 37480 Karlshamn, Sweden. ${ }^{2}$ Department of Medicine, Blekingesjukhuset, Karlshamn, 37480 Karlshamn, Sweden.

Received: 9 January 2012 Accepted: 14 May 2012

Published: 31 May 2012

\section{References}

1. The Diabetes Control and Complications Trial Research Group: The effect of intensive treatment of diabetes on the development and progression of long-term complications in insulin-dependent diabetes mellitus. N Engl J Med 1993, 329:977-986.

2. The Diabetes Control and Complications Trial/Epidemiology of Diabetes Interventions and Complications (DCCT/EDIC) Study Research Group: Intensive diabetes treatment and cardiovascular disease in patients with type 1 diabetes. N Engl J Med 2005, 353:2643-2653.

3. Waldron S: Controversies in the dietary management of diabetes in childhood and adolescence. Br J Hosp Med 1996, 56(8):450-454. 
4. Heinemann L: Variability of insulin absorption and insulin action. Diabetes Technol Ther 2002, 4(5):673-682.

5. Bernstein RK: Virtually continous euglycemia for $5 \mathrm{yr}$ in a labile juvenile onset diabetic patient under noninvasive closed-loop control. Diabetes Care 1980, 3(1):140-143.

6. Bernstein RK: Dr. Bernstein's Diabetes Solution. New York: Little Brown and Company; 1997.

7. O'Neill DF, Westman EC, Bernstein RK: The effects of a low-carbohydrate regimen on glycemic control and serum lipids in diabetes mellitus. Metab Syndr Relat Disord 2003, 1(4):291-298.

8. Nielsen JV, Joensson E: Low-carbohydrate diet in type 2 diabetes: stable improvement of bodyweight and glycemic control during 44 months follow-up. Nutr Metab (Lond) 2008, 5:14.

9. Nielsen JV, Jönsson E, Ivarsson I: A low carbohydrate diet in type 1 diabetes: clinical experience - A brief report. Ups J Med Sci 2005, 110(3):267-273.

10. Higgins $T$, Saw $S$, Sikaris $K$, Wiley $C L$, Cembrowski GC, Lyon AW, et al: Seasonal variation in hemoglobin A1c: is it the same in both hemispheres? J Diabetes Sci Technol 2009, 3(4):668-671.

11. Stampfer MJ, Sacks FM, Salvini S, Willet WC, Hennekens CH: A prospective study of cholesterol, apolipoproteins, and the risk of myocardial infarction. N Engl J Med 1991, 325:373-381.

12. Accurso A, Bernstein RK, Dahlqvist A, Draznin B, Feinman RD, Fine EJ, Gleed A, Jacobs DB, Larson G, Lustig RH, Manninen AH, McFarlane SI, Morrison K, Nielsen JV, Ravnskov U, Roth KS, Silvestre R, Sowers JR, Sundberg R, Volek JS, Westman EC, Wood RJ, Wortman J, Vernon MC: Dietary carbohydrate restriction in type 2 diabetes mellitus and metabolic syndrome: time for a critical appraisal. Nutr Metab (Lond) 2008, 5:9.

13. Ravnskov U: The questionable role of saturated and polyunsaturated fatty acids in cardiovascular disease. J Clin Epidemiol 1998, 51(6):443-460

14. Howard BV, Horn LV, Hsia J, Manson JE, Stefanick ML, Wassertheil-Smoller S, Kuller LH, LaCroix AZ, Langer RD, Lasser NL, Lewis CE, Limacher MC, Margolis KL, Mysiw WJ, Ockene JK, Parker ML, Perri MG, Phillips L, Prentice RL, Robbins R, Rossouw JE, Sarto GE, Schatz IJ, Snetselaar LG, Stevens VJ, Tinker LF, Trevisan M, Vitolins MZ, Anderson GL, Annlouise R, Assaf AR, et al: Low-fat dietary pattern and risk of cardiovascular disease: the Women's Health Initiative Randomized Controlled Dietary Modification Trial. JAMA 2006, 295(6):655-666

15. Skeaff $C M$, Miller J: Dietary fat and coronary heart disease: summary of evidence from prospective cohort and randomised controlled trials. Ann Nutr Metab 2009, 55:173-201.

16. Manninen AH: High-protein weight loss diets and purported adverse effects: where is the evidence? Sports Nutr Rev J 2004, 1:45-51.

doi:10.1186/1758-5996-4-23

Cite this article as: Nielsen et al:: Low carbohydrate diet in type 1

diabetes, long-term improvement and adherence:

A clinical audit. Diabetology \& Metabolic Syndrome 2012 4:23.

\section{Submit your next manuscript to BioMed Central and take full advantage of:}

- Convenient online submission

- Thorough peer review

- No space constraints or color figure charges

- Immediate publication on acceptance

- Inclusion in PubMed, CAS, Scopus and Google Scholar

- Research which is freely available for redistribution 